\title{
ISSN.1907-753X
}

\section{Rencana Distribusi dan Operasi Air Bersih dari Embung Kalisat Untuk Masyarakat Desa Kalisat Kecamatan Rembang Kabupaten Pasuruan}

\author{
Departemen Teknik Infrastruktur Sipil Fakultas Vokasi ITS \\ Didik Harijanto, Dwi Indriyani, Bangkit Widya Aji \\ Email: didi_hari@ce.its.ac.id
}

\begin{abstract}
Water takes essential role for human being and othercreature on earth. There is no subsistence of life if there is nowater. In hand with the huge growth of citizen, should be chasedby the availability of health and clean water. Moreover, there aremany supplies of water that can be found, such as ground surfacewater source, under ground water (lake, river) That need to be processed first. In this moment. Kalisat village has built a dam in order to maintaint production of clean water for daily life for itscitizens. Unfortunately, There is no good and settle system to distribute and maintaining the stream of water for confinedcitizen. Planners are targeting the projection clean water services onknown 2041 of $251 \mathrm{~m}^{3} /$ day are met from the dam in the Village of Kalisat district Rembang Pasuruan region. The volume capacity of the dam $57000 \mathrm{~m}^{3}$ and in this plan, will suplay water for 6084 villager.
\end{abstract}

Keywords: Distribution, Dam, Water

Abstrak

Air mempunyai peranan penting dalam kehidupan manusia dan makhluk lainnya di alam ini. Tidak ada satupun kehidupan di dunia ini yang tidak membutuhkan air. Pertumbuhan penduduk harus diikuti dengan ketersediaan air bersih yang sehat dan cukup. Air tersebut dapat berasal dari atas permukaan tanah, bawah, maupun dari tanah (misalnya air sungai, air danau, dan lain sebagainya), dimana sebelum digunakan harus diolah terlebih dahulu. Saat ini di Desa Kalisat telah dibangun embung yang tujuan awalnya untuk memenuhi kebutuhan air bersih di Desa Kalisat. Namun hingga saat ini tidak ada sistem pendistribusian air bersih dari Embung Kalisat tersebut. Perencana menargetkan proyeksi pelayanan air bersih pada tahun 2041 sebesar $251 \mathrm{~m}^{3} / \mathrm{hari}$ terpenuhi dari Embung Kalisat yang berada di Desa Kalisat Kecamatan Rembang Kabupaten Pasuruan dengan volume kapasitas embung sebesar $57.000 \mathrm{~m}^{3}$. Dalam perencanaan ini, diprediksikan penduduk yang akan mendapatkan layanan 6.084 orang.

Kata Kunci: Distribusi, Embung, Air 


\section{Pendahuluan}

Air baku adalah air yang berasal dari sumber air permukaan, cekungan air tanah, dan/atau air hujan yang memenuhi baku mutu tertentu sebagai air baku untuk air minum maupun Mandi Cuci Kakus (MCK). Kebutuhan air baku untuk berbagai keperluan terutama air bersih untuk rumah tangga, tempat umum, dan industri akan terus meningkat seiring berjalannya waktu dengan lajunya pembangunan berbagai sektor dan bidang, serta jumlah penduduk yang terus bertambah. Jumlah penyediaan dan prasarana air baku yang ada saat ini masih relatif terbatas, sehingga belum dapat memenuhi semua kebutuhan tersebut terutama pada saat musim kemarau.

Pada daerah yang sulit air, contoh di Desa Kalisat Kecamatan Rembang Kabupaten Pasuruan. Dibangun Embung Kalisat pada Agustus 2016 yang lalu, dengan tujuan mengatasi kekurangan ketersediaan air bersih khususnya MCK di Desa Kalisat. Namun, masyarakat hanya disediakan bak filter untuk mengambil air bersih dari embung tersebut. Bagi masyarakat sekitar yang jarak nya tidak terlalu jauh hal itu tidak menjadi masalah, tetapi bagi masyarakat Desa Kalisat yang jaraknya cukup jauh akan merugikan dan membuat manfaat embung menjadi tidak optimal.

Sebagai salah satu alternatif pemecahan masalah dalam distribusi air, maka akan direncanakan jaringan distribusi baru dengan sumber air Embung Kalisat dengan menggunakan Hidran Umum atau dengan jaringan pipa sampai ke rumah penduduk, pengaturan/jadwal pembagian air, serta rencana pengembangan jaringan di 25 tahun yang akan datang. Untuk pemilihan sistem distribusi menggunakan Hidran Umum atau jaringan pipa sampai ke rumah penduduk, mempertimbangkan hasil dari 2 motode tersebut, dibandingkan dengan kapasitas embung. Kapasitas embung yang ada harus memenuhi permintaan dari pelanggan, diharapkan dari alternatif tersebut dapat membantu menyalurkan air bersih secara merata dari Embung Kalisat ke rumah-rumah yang ada di Desa Kalisat.

\section{Metodologi}

Metodologi dalam penelitian ini sesuai dengan gambar 1.

\section{Hasil dan Pembahasan}

Analisis Jumlah Penduduk

Tabel 1. Data Penduduk Desa Kalisat

\begin{tabular}{cccc}
\hline $\begin{array}{c}\text { Tahu } \\
\mathrm{n}\end{array}$ & $\begin{array}{c}\text { Jumlah } \\
\text { Pendudu } \\
\mathrm{k}\end{array}$ & $\begin{array}{c}\text { AWAL } \\
\text { TAHU } \\
\mathrm{N}\end{array}$ & $\begin{array}{c}\text { AKHIR } \\
\text { TAHU } \\
\mathrm{N}\end{array}$ \\
\hline 2006 & 4695 & & \\
2007 & 4724 & 4695 & 4724 \\
2008 & 4750 & 4724 & 4750 \\
2009 & 4790 & 4750 & 4790 \\
2010 & 4805 & 4790 & 4805 \\
2011 & 4816 & 4805 & 4816 \\
2012 & 4841 & 4816 & 4841 \\
2013 & 4909 & 4841 & 4909 \\
2014 & 4950 & 4909 & 4950 \\
2015 & 4978 & 4950 & 4978 \\
2016 & 5050 & 4978 & 5050 \\
\hline
\end{tabular}




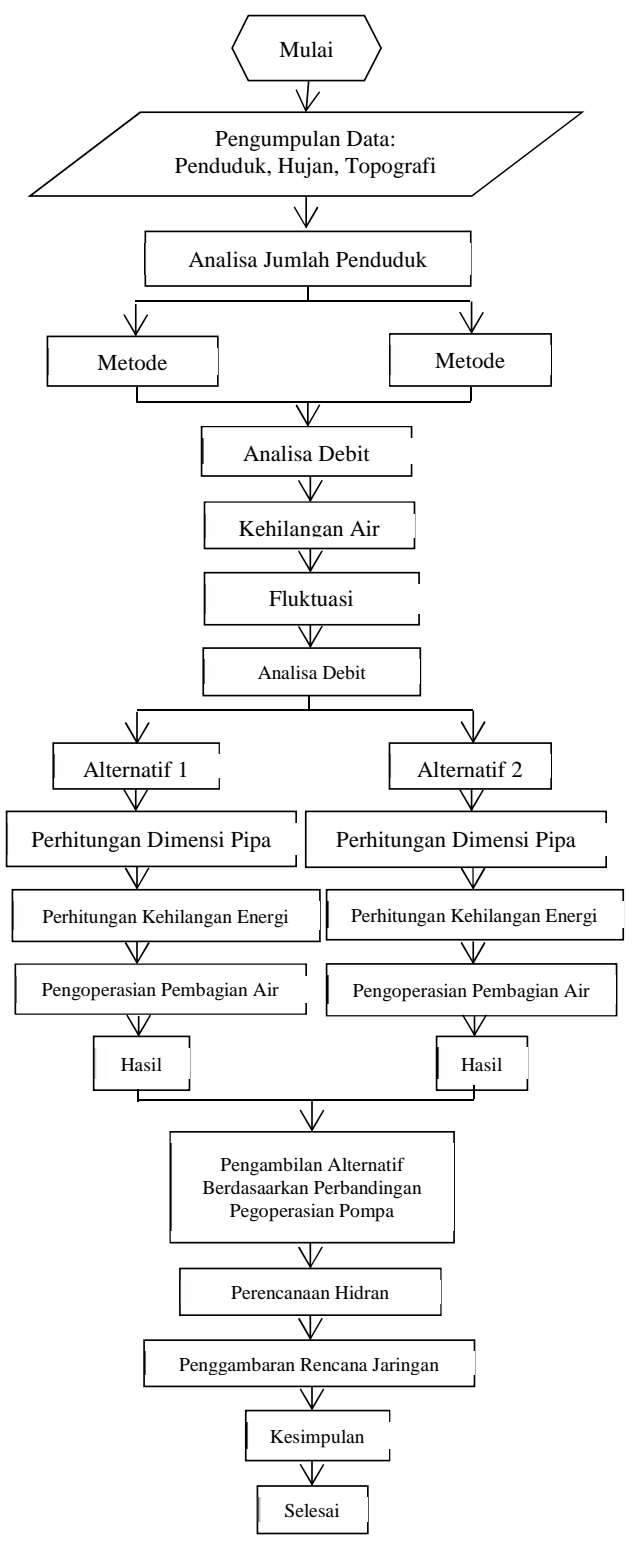

Gambar 1. Bagan Alir Penelitian

Dari data pertumbuhan penduduk pada tabel 1, dapat direncanakan jumlah penduduk tahun yang akan datang. Perencanaan jumlah penduduk dapat menggunakan dua metode yaitu Metode Aritmatika dan Geometrik. Dari kedua metode akan dipilih metode yang mendapatkan nilai korelasi yang paling besar.
Perhitungan pertumbuhan jumlah penduduk sampai tahun 2041 digunakan untuk menentukan kebutuhan air yang akan disuplai di setiap desa, dengan mengalikan jumlah penduduk dengan kebutuhan liter/org/hari.

\section{Perhitungan Proyeksi Penduduk Me- tode Aritmatika}

Perhitungan perkembangan penduduk dengan metode ini digunakan apabila pertumbuhan penduduk meningkat secara konstan, dan persamaan yang digunakan adalah:

$P n=a+n b$

$b=\frac{a-p o}{m}$

Jumlah penduduk Desa Kalisat di tahun 2041 terhitung dari tahun 2007 adalah 5937 jiwa.

\section{Perhitungan Proyeksi Penduduk Metode Geometrik}

Metode ini digunakan apabila partumbuhan penduduk meningkat secara berganda dan persamaan yang digunakan adalah :

$P n=P o(1+r)^{n}$

$P=\frac{\alpha-p o}{m \cdot a} \times 100 \%$

Jumlah penduduk Desa Kalisat di tahun 2041 terhitung dari tahun 2007 adalah 6084 jiwa.

\section{Pembagian Zona}

Kepadatan penduduk digunakan untuk membagi zona untuk distribusi air bersih. Kepadatan penduduk dihitung menggunakan persamaan:

kepadatan penduduk $=\frac{\text { iumlah penduduk }(\text { jiwa })}{\text { luas daerah terbangun }(\mathrm{Ha})}$

Gambar pembagian zona distrbusi air di

Desa Kalisat dapat dilihat di gambar 2. 


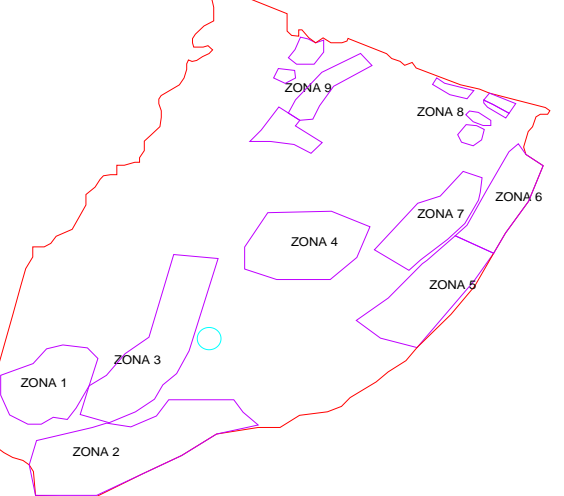

Gambar 2. Pembagian Zona

Berdasarkan hasil perhitungan didapatkan luas masing-masing zona dan jumlah penduduk untuk setiap zona dapat dilihat di tabel 2.

Tabel 2. Pembagian Zona dan Jumlah Penduduk

\begin{tabular}{ccc}
\hline ZONA & LUAS & $\begin{array}{c}\text { JUMLAH PENDUDUK } \\
\text { Ha }\end{array}$ \\
\hline 1 & 16,38 & 593 \\
2 & 34,85 & 1261 \\
3 & 26,95 & 975 \\
4 & 21,03 & 863 \\
5 & 19,68 & 712 \\
6 & 12,62 & 457 \\
7 & 14,02 & 507 \\
8 & 7,34 & 266 \\
9 & 12,47 & 451 \\
Jumlah & & 6048 \\
\hline
\end{tabular}

Sumber: hasil perhitungan

\section{Perhitungan Kebutuhan Air Bersih}

Air bersih di Desa Kalisat dicukupi dengan hidran, direncanakan debit Hidran Umum (HU) sebesar 60 1/hari/orang (petunjuk praktis perencanaan pembangunan sistem penyediaan air bersih pedesaan).

Kebutuhan air Desa Kalisat pada tahun proyeksi 2041 dapat dilihat di tabel 3.

Kebutuhan air total (Qtotal) di Desa Kalisat adalah sebesar 0,0029153 m³/dt.
Perhitungan fluktuasi penggunaan

air

Pada umumnya kebutuhan air di masyarakat relatif atau tidak selalu konstan, karena adanya kebiasaan pemakaian debit air yang tidak menentu pada setiap jam.

Debit rata - rata $=$ diambil dari Qtotal kebutuhan air

Pemakaian air $=$ debit rata-rata $\mathrm{x}$ koefisien Hasil perhitungan fluktuasi penggunaan air dapat dilihat pada tabel 4.

Perhitungan Kapasitas Reservoir Metode Operasional

Perhitungan kapasitas reservoir menggunakan Metode Operasional Rumus yang digunakan adalah

Debit = inflow - outflow

Outflow $\left(\mathrm{m}^{3}\right)$ = pemakaian air jam ke X Inflow $\left(\mathrm{m}^{3}\right)=$ Debit Rata rata

Setelah mencari debit pada setiap jam nya, nilai positif dan negatif dijumlahkan semua, maka akan menghasilkan nilai yang sama. Untuk bilangan negatif berubah tanda menjadi positif. Hasil penjumlahan debit selama 24 jam dapat dilihat di tabel 5.

\section{Perhitungan Kapasitas Reservoir Metode Kurva S}

Untuk perhitungan menggunakan Metode Kurva S maka pemakaian air per jam dan produksi air per jam semua nilai dikomulatifkan.

Komulatif pemakaian jam ke $\mathrm{X}=$ komulatif pemakaian jam X-1 + pemakaian air jam ke $X$.

Komulatif produksi jam ke $\mathrm{X}=$ komulatif produksi jam ke X-1 + produksi jam ke X. 


\section{ISSN.1907-753X}

Deposit didapatkan dari produksi dikurangi komulatif pemakaian.

Kapasitas reservoir didapatkan dari nilai maksimum deposit dikurangi nilai minimum deposit
$=28.4-(-9.79)=38.22 \mathrm{~m}^{3}$.

Kapasitas reservoir metode kurva $\mathrm{S}$ dapat dilihat di tabel 6 .

Tabel 3. Kebutuhan Air Bersih

\begin{tabular}{ccccccc}
\hline & Zona & $\begin{array}{c}\text { Jumlah } \\
\text { penduduk } \\
\text { jiwa }\end{array}$ & \% pelayanan & $\begin{array}{c}\text { Penduduk } \\
\text { terlayani } \\
\text { jiwa }\end{array}$ & $\begin{array}{c}\text { Lhu } \\
\text { buah }\end{array}$ & $\begin{array}{c}\text { Kebutuhan air } \\
\text { hu } \\
m^{3} / d t\end{array}$ \\
\hline 1 & HU 1 & 593 & $100 \%$ & 593 & 1 & 0.0002 \\
2 & HU 2A & 1261 & $60 \%$ & 757 & 2 & 0.0003 \\
& HU 2B & & $40 \%$ & 504 & & 0.0002 \\
3 & HU 3 & 975 & $100 \%$ & 975 & 1 & 0.0003 \\
4 & HU 4A & 863 & $60 \%$ & 518 & 2 & 0.0002 \\
& HU 4B & & $40 \%$ & 345 & & 0.0001 \\
5 & HU 5A & 712 & $60 \%$ & 427 & 2 & 0.0001 \\
& HU 5B & & $40 \%$ & 285 & & 0.0001 \\
6 & HU 6A & 457 & $60 \%$ & 274 & 2 & 0.0001 \\
& HU 6B & & $40 \%$ & 183 & & 0.00007 \\
7 & HU 7A & 507 & $60 \%$ & 304 & 2 & 0.0001 \\
& HU 7B & & $40 \%$ & 203 & & 0.00008 \\
8 & HU 8 & 266 & $100 \%$ & 266 & 1 & 0.0001 \\
9 & HU 9A & 451 & $60 \%$ & 271 & 2 & 0.0001 \\
& HU 9B & & $40 \%$ & 180 & & 0.000071 \\
\hline
\end{tabular}

Sumber : hasil perhitungan

Tabel 4. Fluktuasi Penggunaan Air

\begin{tabular}{|c|c|c|c|c|c|}
\hline JAM KE- & Waktu & Koefisien & $\begin{array}{c}\text { Debit rata-rata } \\
\mathrm{m}^{3} / \mathrm{jam}\end{array}$ & $\begin{array}{c}\text { Pemakaian Air } \\
\mathrm{m}^{3} / \mathrm{jam}\end{array}$ & $\begin{array}{c}\text { Pemakaian Air Komulatif } \\
\mathrm{m}^{3} / \mathrm{jam}\end{array}$ \\
\hline 1 & $00.00-01.00$ & 0.53 & 8.75 & 4.64 & 4.64 \\
\hline 2 & $01.00-02.00$ & 0.45 & 8.75 & 3.94 & 8.57 \\
\hline 3 & $02.00-03.00$ & 0.40 & 8.75 & 3.50 & 12.07 \\
\hline 4 & $03.00-04.00$ & 0.40 & 8.75 & 3.50 & 15.57 \\
\hline 5 & $04.00-05.00$ & 0.45 & 8.75 & 3.94 & 19.50 \\
\hline 6 & $05.00-06.00$ & 0.62 & 8.75 & 5.42 & 24.93 \\
\hline 7 & $06.00-07.00$ & 0.90 & 8.75 & 7.87 & 32.80 \\
\hline 8 & $07.00-08.00$ & 1.40 & 8.75 & 12.24 & 45.04 \\
\hline 9 & $08.00-09.00$ & 1.30 & 8.75 & 11.37 & 56.41 \\
\hline 10 & $09.00-10.00$ & 1.25 & 8.75 & 10.93 & 67.34 \\
\hline 11 & $10.00-11.00$ & 1.20 & 8.75 & 10.49 & 77.84 \\
\hline 12 & $11.00-12.00$ & 1.20 & 8.75 & 10.49 & 88.33 \\
\hline 13 & $12.00-13.00$ & 1.20 & 8.75 & 10.49 & 98.83 \\
\hline 14 & $13.00-14.00$ & 1.25 & 8.75 & 10.93 & 109.76 \\
\hline 15 & $14.00-15.00$ & 1.30 & 8.75 & 11.37 & 121.13 \\
\hline 16 & $15.00-16.00$ & 1.30 & 8.75 & 11.37 & 132.50 \\
\hline 17 & $16.00-17.00$ & 1.42 & 8.75 & 12.42 & 144.92 \\
\hline 18 & $17.00-18.00$ & 1.50 & 8.75 & 13.12 & 158.04 \\
\hline 19 & $18.00-19.00$ & 1.55 & 8.75 & 13.56 & 171.59 \\
\hline 20 & $19.00-20.00$ & 1.40 & 8.75 & 12.24 & 183.84 \\
\hline 21 & $20.00-21.00$ & 1.10 & 8.75 & 9.62 & 193.46 \\
\hline 22 & $21.00-22.00$ & 0.75 & 8.75 & 6.56 & 200.02 \\
\hline 23 & $22.00-23.00$ & 0.60 & 8.75 & 5.25 & 205.26 \\
\hline 24 & $23.00-24.00$ & 0.53 & 8.75 & 4.64 & 209.90 \\
\hline \multicolumn{2}{|c|}{ Jumlah } & 24.00 & 209.90 & 209.90 & \\
\hline
\end{tabular}

Sumber : hasil perhitungan 
Perhitungan Hidran Umum

Perhitungan dimensi hidran umum dipengaruhi oleh jumlah kebutuhan air dan lama waktu layanan. Menggunakan Hidran Umum persegi panjang. Direncanakan $\mathrm{T}=1 \mathrm{~m}, \mathrm{P}: \mathrm{L}=1: 1$.
Kapasitas mati $0.5 \mathrm{~m}$ dan tinggi ruang udara $0.5 \mathrm{~m}$

$$
\begin{aligned}
\mathrm{VHU} & =\mathrm{PxLxT} \\
10.22 & =\mathrm{L}^{2} \mathrm{x} 2 \\
10.22 & =\mathrm{L}^{2} \\
\mathrm{~L} & =3.20 \mathrm{~m} \\
\mathrm{P} & =\mathrm{L} \\
\mathrm{P} & =3.20 \mathrm{~m}
\end{aligned}
$$

\begin{tabular}{|c|c|c|c|c|}
\hline No. & Waktu & $\begin{array}{c}\text { A } \\
\text { Outflow }\left(\mathrm{m}^{3} / \mathrm{jam}\right)\end{array}$ & $\begin{array}{c}\text { B } \\
\text { Inflow }\left(\mathrm{m}^{3} / \mathrm{jam}\right)\end{array}$ & Debit \\
\hline 1 & $00.00-01.00$ & 4.64 & 8.75 & 4.11 \\
\hline 2 & $01.00-02.00$ & 3.94 & 8.75 & 4.81 \\
\hline 3 & $02.00-03.00$ & 3.50 & 8.75 & 5.25 \\
\hline 4 & $03.00-04.00$ & 3.50 & 8.75 & 5.25 \\
\hline 5 & $04.00-05.00$ & 3.94 & 8.75 & 4.81 \\
\hline 6 & $05.00-06.00$ & 5.42 & 8.75 & 3.32 \\
\hline 7 & $06.00-07.00$ & 7.87 & 8.75 & 0.87 \\
\hline 8 & $07.00-08.00$ & 12.24 & 8.75 & -3.50 \\
\hline 9 & 08.00-09.00 & 11.37 & 8.75 & -2.62 \\
\hline 10 & 09.00-10.00 & 10.93 & 8.75 & -2.19 \\
\hline 11 & $10.00-11.00$ & 10.49 & 8.75 & -1.75 \\
\hline 12 & $11.00-12.00$ & 10.49 & 8.75 & -1.75 \\
\hline 13 & $12.00-13.00$ & 10.49 & 8.75 & -1.75 \\
\hline 14 & $13.00-14.00$ & 10.93 & 8.75 & -2.19 \\
\hline 15 & $14.00-15.00$ & 11.37 & 8.75 & -2.62 \\
\hline 16 & $15.00-16.00$ & 11.37 & 8.75 & -2.62 \\
\hline 17 & $16.00-17.00$ & 12.42 & 8.75 & -3.67 \\
\hline 18 & $17.00-18.00$ & 13.12 & 8.75 & -4.37 \\
\hline 19 & $18.00-19.00$ & 13.56 & 8.75 & -4.81 \\
\hline 20 & $19.00-20.00$ & 12.24 & 8.75 & -3.50 \\
\hline 21 & $20.00-21.00$ & 9.62 & 8.75 & -0.87 \\
\hline 22 & $21.00-22.00$ & 6.56 & 8.75 & 2.19 \\
\hline 23 & $22.00-23.00$ & 5.25 & 8.75 & 3.50 \\
\hline \multirow[t]{2}{*}{24} & $23.00-24.00$ & 4.64 & 8.75 & 4.11 \\
\hline & Jumlah : & & & 38.22 \\
\hline
\end{tabular}

\begin{tabular}{|c|c|c|c|c|c|c|}
\hline No & Waktu & $\begin{array}{l}\text { Pem. Air Per Jam } \\
\left(\mathrm{m}^{3}\right)\end{array}$ & $\begin{array}{l}\text { Prod. Air Bersih } \\
\quad\left(\mathrm{m}^{3} / \mathrm{jam}\right)\end{array}$ & $\begin{array}{l}\text { Kom. Pemakaian } \\
\left(\mathrm{m}^{3}\right)\end{array}$ & $\begin{array}{c}\text { Produksi } \\
\left(\mathrm{m}^{3}\right)\end{array}$ & $\begin{array}{c}\text { Deposit } \\
\left(\mathrm{m}^{3}\right)\end{array}$ \\
\hline 1 & $00.00-01.00$ & 4.64 & 8.75 & 4.64 & 8.75 & 4.11 \\
\hline 2 & $01.00-02.00$ & 3.94 & 8.75 & 8.57 & 17.49 & 8.92 \\
\hline 3 & $02.00-03.00$ & 3.50 & 8.75 & 12.07 & 26.24 & 14.17 \\
\hline 4 & $03.00-04.00$ & 3.50 & 8.75 & 15.57 & 34.98 & 19.42 \\
\hline 5 & $04.00-05.00$ & 3.94 & 8.75 & 19.50 & 43.73 & 24.23 \\
\hline 6 & $05.00-06.00$ & 5.42 & 8.75 & 24.93 & 52.47 & 27.55 \\
\hline 7 & $06.00-07.00$ & 7.87 & 8.75 & 32.80 & 61.22 & 28.42 \\
\hline 8 & $07.00-08.00$ & 12.24 & 8.75 & 45.04 & 69.97 & 24.93 \\
\hline 9 & 08.00-09.00 & 11.37 & 8.75 & 56.41 & 78.71 & 22.30 \\
\hline 10 & 09.00-10.00 & 10.93 & 8.75 & 67.34 & 87.46 & 20.12 \\
\hline 11 & $10.00-11.00$ & 10.49 & 8.75 & 77.84 & 96.20 & 18.37 \\
\hline 12 & $11.00-12.00$ & 10.49 & 8.75 & 88.33 & 104.95 & 16.62 \\
\hline 13 & $12.00-13.00$ & 10.49 & 8.75 & 98.83 & 113.69 & 14.87 \\
\hline 14 & $13.00-14.00$ & 10.93 & 8.75 & 109.76 & 122.44 & 12.68 \\
\hline 15 & $14.00-15.00$ & 11.37 & 8.75 & 121.13 & 131.19 & 10.06 \\
\hline 16 & $15.00-16.00$ & 11.37 & 8.75 & 132.50 & 139.93 & 7.43 \\
\hline 17 & $16.00-17.00$ & 12.42 & 8.75 & 144.92 & 148.68 & 3.76 \\
\hline 18 & $17.00-18.00$ & 13.12 & 8.75 & 158.04 & 157.42 & -0.61 \\
\hline 19 & $18.00-19.00$ & 13.56 & 8.75 & 171.59 & 166.17 & -5.42 \\
\hline 20 & $19.00-20.00$ & 12.24 & 8.75 & 183.84 & 174.92 & -8.92 \\
\hline 21 & $20.00-21.00$ & 9.62 & 8.75 & 193.46 & 183.66 & -9.80 \\
\hline 22 & $21.00-22.00$ & 6.56 & 8.75 & 200.02 & 192.41 & -7.61 \\
\hline 23 & $22.00-23.00$ & 5.25 & 8.75 & 205.26 & 201.15 & -4.11 \\
\hline 24 & $23.00-24.00$ & 4.64 & 8.75 & 209.90 & 209.90 & 0.00 \\
\hline
\end{tabular}

Tabel 5. Metode Operasional

Sumber : Hasil Perhitungan

Tabel 6. Metode Kurva S

Sumber : hasil perhitungan 
Didapatkan dimensi HU $1 \mathrm{P}=3.20 \mathrm{~m}$, $\mathrm{L}=3.20 \mathrm{~m}, \mathrm{~T}=2 \mathrm{~m}$. Gambar hidran umum dapat dilihat pada gambar 3 . Rekapitulasi dimensi Hidran Umum dapat dilihat di tabel 7.

\section{Rencana jaringan pipa alternatif 1}

Gambar rencana jaringan pipa alternatif 1 dapat dilihat pada gambar 4

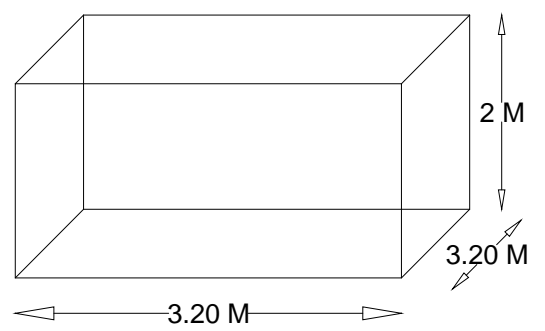

Gambar 3. Dimensi Hidran Umum

Tabel 7. Rekapitulasi Dimensi Hidran Umum

\begin{tabular}{ccccccc}
\hline Hidran & $\begin{array}{c}\mathbf{Q} \\
\mathrm{m}^{3} / \mathrm{jam}\end{array}$ & $\begin{array}{c}\text { V Hu } \\
\mathrm{m}^{3}\end{array}$ & \multicolumn{3}{c}{ Dimensi Hu $(\mathbf{m})$} \\
$\mathrm{y}$ & $\mathrm{p}$ & $\mathrm{l}$ & $\mathrm{T}$ \\
\hline HU 1 & 0.85 & 10.22 & 3.20 & 3.20 & 2 \\
HU 2A & 1.09 & 13.05 & 3.61 & 3.61 & 2 \\
HU 2B & 0.73 & 8.70 & 2.95 & 2.95 & 2 \\
HU 3 & 1.40 & 16.82 & 4.10 & 4.10 & 2 \\
HU 4A & 0.74 & 8.93 & 2.99 & 2.99 & 2 \\
HU 4B & 0.50 & 5.95 & 2.44 & 2.44 & 2 \\
HU 5A & 0.61 & 7.37 & 2.71 & 2.71 & 2 \\
HU 5B & 0.41 & 4.91 & 2.22 & 2.22 & 2 \\
HU 6A & 0.39 & 4.73 & 2.17 & 2.17 & 2 \\
HU 6B & 0.26 & 3.15 & 1.78 & 1.78 & 2 \\
HU 7A & 0.44 & 5.25 & 2.29 & 2.29 & 2 \\
HU 7B & 0.29 & 3.50 & 1.87 & 1.87 & 2 \\
HU 8 & 0.38 & 4.58 & 2.14 & 2.14 & 2 \\
HU 9A & 0.39 & 4.67 & 2.16 & 2.16 & 2 \\
HU 9B & 0.26 & 3.11 & 1.76 & 1.76 & 2 \\
\hline Sumber $:$ hasil perhitungan & & &
\end{tabular}

\section{Rencana jaringan pipa alternatif 2}

Gambar rencana jaringan pipa alternatif 2 dapat dilihat pada gambar 5 .

\section{Perhitungan Dimensi Pipa}

Dimensi pipa sangat penting untuk diperhitungkan karena dalam perencanaan distribusi jaringan perpipaan membutuhkan biaya yang sangat besar. Walaupun dalam penelitian ini tidak membahas tentang anggaran biaya. Perhitungan dimensi pipa dimaksudkan untuk menentukan dimensi pipa yang efektif dan efisien.

Perhitungan dimensi pipa menggunakan rumus :

$Q=A x V$

Rekapitulasi Dimensi pipa dapat dilihat di tabel 8 dan tabel 9.

Gambar 4. Rencana Jaringan Pipa Alternatif 1

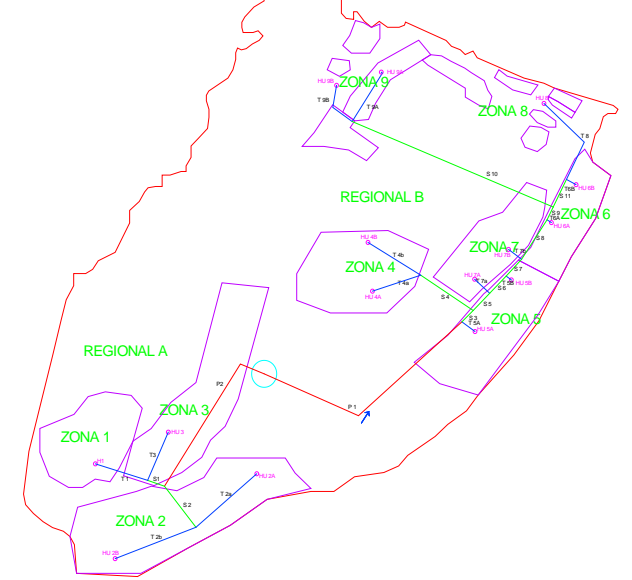

Gambar 5. Rencana Jaringan Pipa Alternatif 2 
Tabel 8. Dimensi Pipa Alternatif 1

\begin{tabular}{crccccc}
\hline PIPA & $\begin{array}{c}\text { PANJANG } \\
\mathrm{m}\end{array}$ & $\begin{array}{c}\text { D pipa } \\
\mathrm{mm}\end{array}$ & $\begin{array}{c}\text { Q renana } \\
\mathrm{m}^{3 / / \mathrm{dt}}\end{array}$ & $\mathrm{Fp}$ & $\begin{array}{c}\text { Q pipa } \\
\mathrm{m}^{3} / \mathrm{dt}\end{array}$ & $\begin{array}{c}\text { V pipa } \\
\mathrm{m} / \mathrm{s}\end{array}$ \\
\hline T1 & 278.2 & 42 & 0.0002 & 1.5 & 0.00035502 & 0.3 \\
T 2A & 401.2 & 48 & 0.0003 & 1.5 & 0.00045314 & 0.3 \\
T2B & 438.8 & 42 & 0.0002 & 1.5 & 0.00030209 & 0.3 \\
T3 & 252 & 48 & 0.0003 & 1.5 & 0.00058402 & 0.4 \\
T 4A & 352.6 & 42 & 0.0002 & 1.5 & 0.00030999 & 0.3 \\
T 4B & 340.2 & 32 & 0.0001 & 1.5 & 0.00020666 & 0.3 \\
T 9A & 276.5 & 32 & 0.0001 & 1.5 & 0.00016216 & 0.3 \\
T 9B & 225.9 & 26 & 0.00007 & 1.5 & 0.00010810 & 0.3 \\
S1 & 90.4 & 76 & 0.0006 & 1.5 & 0.00093904 & 0.3 \\
S2 & 252.7 & 60 & 0.0005 & 1.5 & 0.00075523 & 0.3 \\
S9 & 858.0 & 36 & 0.0001 & 1.5 & 0.00027026 & 0.3 \\
S10 & 560.5 & 60 & 0.0005 & 1.5 & 0.00078691 & 0.3 \\
P2 & 697.6 & 89 & 0.001 & 1.5 & 0.00169427 & 0.3 \\
P3 & 130.1 & 114 & 0.001 & 1.5 & 0.00248118 & 0.3 \\
T 5A & 81.2 & 36 & 0.0001 & 1.5 & 0.00025587 & 0.3 \\
T 5B & 32.2 & 32 & 0.0001 & 1.5 & 0.00017058 & 0.3 \\
T 6A & 25.7 & 32 & 0.0001 & 1.5 & 0.00016411 & 0.3 \\
T 6B & 55.2 & 26 & 0.00007 & 1.5 & 0.00010941 & 0.3 \\
T 7A & 104.8 & 32 & 0.0001 & 1.5 & 0.00018229 & 0.3 \\
T 7B & 89.78 & 26 & 0.00008 & 1.5 & 0.00012153 & 0.3 \\
T 8 & 474.81 & 26 & 0.0001 & 1.5 & 0.00015909 & 0.3 \\
S3 & 740.9 & 76 & 0.0007 & 1.5 & 0.00116288 & 0.3 \\
S4 & 212.5 & 60 & 0.0006 & 1.5 & 0.00090702 & 0.4 \\
S5 & 100.6 & 60 & 0.0004 & 1.5 & 0.00072472 & 0.3 \\
S6 & 118.5 & 48 & 0.0003 & 1.5 & 0.00055414 & 0.4 \\
S7 & 223.5 & 48 & 0.0002 & 1.5 & 0.00043261 & 0.3 \\
S8 & 215.7 & 36 & 0.0001 & 1.5 & 0.00026850 & 0.3 \\
P1 & 423.5 & 89 & 0.0009 & 1.5 & 0.00141875 & 0.3 \\
\hline S & & & & &
\end{tabular}

Sumber : hasil perhitungan

Tabel 9. Dimensi Pipa Alternatif 2

\begin{tabular}{crccccc}
\hline PIPA & $\begin{array}{c}\text { PANJANG } \\
\mathrm{m}\end{array}$ & $\begin{array}{c}\text { D pipa } \\
\mathrm{mm}\end{array}$ & $\begin{array}{c}\text { Qrencana } \\
\mathrm{m}^{3} / \mathrm{dt}\end{array}$ & $\mathrm{Fp}$ & $\begin{array}{c}\text { Q pipa } \\
\mathrm{m}^{3} / \mathrm{dt}\end{array}$ & $\begin{array}{c}\text { V pipa } \\
\mathrm{m} / \mathrm{s}\end{array}$ \\
\hline T1 & 278.2 & 42 & 0.000237 & 1.5 & 0.00035502 & 0.3 \\
T 2A & 401.2 & 42 & 0.000302 & 1.5 & 0.00045314 & 0.4 \\
T2B & 438.8 & 42 & 0.000201 & 1.5 & 0.00030209 & 0.3 \\
T3 & 252.0 & 60 & 0.000389 & 1.5 & 0.00058402 & 0.3 \\
S1 & 90.4 & 60 & 0.000626 & 1.5 & 0.00093904 & 0.4 \\
S2 & 252.7 & 60 & 0.000503 & 1.5 & 0.00075523 & 0.3 \\
P2 & 827.6 & 89 & 0.001088 & 1.5 & 0.00163166 & 0.3 \\
T 4A & 258.1 & 42 & 0.000207 & 1.5 & 0.00030999 & 0.3 \\
T 4B & 311.1 & 32 & 0.000138 & 1.5 & 0.00020666 & 0.3 \\
T 5A & 81.2 & 36 & 0.000171 & 1.5 & 0.00025587 & 0.3 \\
T 5B & 32.2 & 32 & 0.000114 & 1.5 & 0.00017058 & 0.3 \\
T 6A & 25.7 & 32 & 0.000109 & 1.5 & 0.00016411 & 0.3 \\
T 6B & 55.2 & 26 & 0.000073 & 1.5 & 0.00010941 & 0.3 \\
T 7A & 102.1 & 32 & 0.000122 & 1.5 & 0.00018229 & 0.3 \\
T 7B & 81.5 & 26 & 0.000081 & 1.5 & 0.00012153 & 0.3 \\
T 8 & 474.9 & 26 & 0.000106 & 1.5 & 0.00015909 & 0.3 \\
T 9A & 276.5 & 32 & 0.000108 & 1.5 & 0.00016216 & 0.3 \\
T 9B & 226.0 & 26 & 0.000072 & 1.5 & 0.00010810 & 0.3 \\
S3 & 79.1 & 89 & 0.001129 & 1.5 & 0.00169392 & 0.3 \\
S4 & 316.1 & 48 & 0.000344 & 1.5 & 0.00051665 & 0.3 \\
S5 & 117.1 & 76 & 0.000785 & 1.5 & 0.00117727 & 0.3 \\
S6 & 117.1 & 76 & 0.000663 & 1.5 & 0.00099498 & 0.3 \\
S7 & 112.3 & 60 & 0.000550 & 1.5 & 0.00082440 & 0.3 \\
S8 & 228.0 & 60 & 0.000469 & 1.5 & 0.00070287 & 0.3 \\
S9 & 68.1 & 48 & 0.000359 & 1.5 & 0.00053876 & 0.3 \\
S10 & 1103.9 & 32 & 0.000180 & 1.5 & 0.00027026 & 0.4 \\
S11 & 147.5 & 32 & 0.000179 & 1.5 & 0.00026850 & 0.4 \\
P1 & 1212.0 & 89 & 0.001300 & 1.5 & 0.00194979 & 0.4 \\
\hline S4 & & & & &
\end{tabular}

Sumber : hasil perhitungan 
Perhitungan kehilangan energi akibat mayor losses

Kehilangan energi akibat kekasaran pipa dapat dihitung sebagai berikut : $H f=\left(\frac{Q}{0.2785 x C x D^{2.68}}\right)^{2.85} x L$

\section{Perhitungan Kehilangan Akibat Belokan Pipa (Minor Losses)}

Kehilangan tekanan akibat adanya belokan, percabangan, dan aksesoris pipa (10\% dari mayor loses) disebut minor losses. $H f=K \cdot \frac{V^{2}}{2 g}$ $\mathrm{K}=$ koefisien akibat belokan pipa (tabel 10)

Tabel 10. Koefisien akibat belokan pipa

\begin{tabular}{rrrrrrrr}
\hline$\alpha$ & 5 & 10 & 15 & 30 & 45 & 60 & 90 \\
\hline \multirow{2}{*}{$\mathrm{k}$} & 0.0 & 0.0 & 0.0 & 0.1 & & 0.5 & \\
& 2 & 4 & 5 & 5 & 0.28 & 5 & 1.2 \\
\hline
\end{tabular}

(Sumber : Bambang. 2008)

Contoh :

$$
\begin{array}{ll}
\alpha & =77^{\circ} \\
\alpha 1 & =60^{\circ} \\
\alpha 2 & =90^{\circ} \\
\mathrm{k} 1 & =0.55 \\
\mathrm{k} 2 & =1.2
\end{array}
$$$$
k=0.55+\frac{1.2}{0.55} \times 77-60
$$$$
=0.918
$$

\section{Perhitungan Kehilangan energi total}

Rekapitulasi perhitungan kehilangan energi total dapat dilihat pada tabel 11 dan tabel 12.

\section{Perhitungan Head Pompa}

Head total pompa yang harus disediakan untuk mengalirkan sejumlah air seperti yang direncanakan dapat ditentukan berdasarkan kondisi instalasi yang akan dilayani pompa. Perhitungan total head pompa dapat dihitung berdasarkan persamaan

\begin{tabular}{|c|c|c|c|c|c|}
\hline No & Pipa & Jenis pipa & $\begin{array}{c}\text { Mayor } \\
\text { losses }\end{array}$ & $\begin{array}{l}\text { Minor } \\
\text { losses }\end{array}$ & Hf total \\
\hline 1 & $\mathrm{~T} 1$ & Tersier & 0.58 & & 0.58 \\
\hline 2 & $\mathrm{~T} 2 \mathrm{a}$ & Tersier & 0.69 & & 0.69 \\
\hline 3 & $\mathrm{~T} 2 \mathrm{~b}$ & Tersier & 0.68 & & 0.68 \\
\hline 4 & $\mathrm{~T} 3$ & Tersier & 0.69 & & 0.69 \\
\hline 5 & $\mathrm{~T} 4 \mathrm{a}$ & Tersier & 0.57 & & 0.57 \\
\hline 6 & $\mathrm{~T} 4 \mathrm{~b}$ & Tersier & 0.98 & & 0.98 \\
\hline 7 & Т 9a & Tersier & 0.51 & & 0.51 \\
\hline 8 & $\mathrm{~T} 9 \mathrm{~b}$ & Tersier & 0.54 & & 0.54 \\
\hline 9 & S1 & Sekunder & 0.06 & & 0.06 \\
\hline 10 & S2 & Sekunder & 0.37 & & 0.37 \\
\hline 11 & S9 & Sekunder & 2.28 & 0.01 & 2.29 \\
\hline 12 & $\mathrm{~S} 10$ & Sekunder & 0.90 & & 0.90 \\
\hline 13 & P2 & Primer & 0.68 & & 0.68 \\
\hline 14 & P3 & Primer & 0.08 & & 0.08 \\
\hline Hf regional a & & & 9.60 & & 9.60 \\
\hline 15 & T 5a & Tersier & 0.20 & & 0.20 \\
\hline 16 & $\mathrm{~T} 5 \mathrm{~b}$ & Tersier & 0.06 & 0.00 & 0.07 \\
\hline 17 & T $6 \mathrm{a}$ & Tersier & 0.05 & & 0.05 \\
\hline 18 & $\mathrm{~T} 6 \mathrm{~b}$ & Tersier & 0.13 & & 0.13 \\
\hline 19 & $\mathrm{~T} 7 \mathrm{a}$ & Tersier & 0.24 & & 0.24 \\
\hline 20 & $\mathrm{~T} 7 \mathrm{~b}$ & Tersier & 0.27 & & 0.27 \\
\hline 21 & T 8 & Tersier & 2.31 & & 2.31 \\
\hline 22 & S3 & Sekunder & 0.77 & & 0.77 \\
\hline 23 & S4 & Sekunder & 0.44 & & 0.44 \\
\hline 24 & S5 & Sekunder & 0.14 & & 0.14 \\
\hline 25 & S6 & Sekunder & 0.29 & & 0.29 \\
\hline 26 & S7 & Sekunder & 0.35 & & 0.35 \\
\hline 27 & S8 & Sekunder & 0.57 & & 0.57 \\
\hline 28 & P1 & Primer & 0.30 & 0.00 & 0.30 \\
\hline Hf regional b & & & 6.12 & & 6.12 \\
\hline
\end{tabular}
berikut :

$$
H=\Gamma_{f}+Z b+\frac{v^{2}}{2 g}
$$

\begin{tabular}{|c|c|c|c|c|c|}
\hline No & Pipa & Jenis pipa & $\begin{array}{l}\text { Mayor } \\
\text { losses }\end{array}$ & $\begin{array}{l}\text { Minor } \\
\text { losses }\end{array}$ & $\mathrm{Hf}$ \\
\hline 1 & $\mathrm{~T} 1$ & Tersier & 0.58 & & 0.58 \\
\hline 2 & T $2 \mathrm{a}$ & Tersier & 1.31 & & 1.31 \\
\hline 3 & $\mathrm{~T} 2 \mathrm{~b}$ & Tersier & 0.68 & & 0.68 \\
\hline 4 & $\mathrm{~T} 3$ & Tersier & 0.23 & & 0.23 \\
\hline 5 & S1 & Sekunder & 0.20 & & 0.20 \\
\hline 6 & $\mathrm{~S} 2$ & Sekunder & 0.37 & & 0.37 \\
\hline 7 & $\mathrm{P} 2$ & Primer & 0.75 & & 0.75 \\
\hline $\begin{array}{c}\text { Hf regional } \\
\mathrm{A}\end{array}$ & & & 4.13 & & 4.13 \\
\hline 8 & T $4 \mathrm{a}$ & Tersier & 0.42 & & 0.42 \\
\hline 9 & $\mathrm{~T} 4 \mathrm{~b}$ & Tersier & 0.89 & & 0.89 \\
\hline 10 & T $5 \mathrm{a}$ & Tersier & 0.20 & & 0.20 \\
\hline 11 & T $5 b$ & Tersier & 0.06 & & 0.06 \\
\hline 12 & $\mathrm{~T} 6 \mathrm{a}$ & Tersier & 0.05 & & 0.05 \\
\hline 13 & $\mathrm{~T} 6 \mathrm{~b}$ & Tersier & 0.13 & & 0.13 \\
\hline 14 & T 7a & Tersier & 0.23 & & 0.23 \\
\hline 15 & T 7b & Tersier & 0.24 & & 0.24 \\
\hline 16 & T 8 & Tersier & 2.31 & 0.00 & 2.31 \\
\hline 17 & T 9a & Tersier & 0.51 & & 0.51 \\
\hline 18 & $\mathrm{~T} 9 \mathrm{~b}$ & Tersier & 0.54 & 0.00 & 0.54 \\
\hline 19 & S3 & Sekunder & 0.08 & & 0.08 \\
\hline 20 & S4 & Sekunder & 0.69 & & 0.69 \\
\hline 21 & S5 & Sekunder & 0.13 & & 0.13 \\
\hline 22 & S6 & Sekunder & 0.09 & & 0.09 \\
\hline 23 & S7 & Sekunder & 0.20 & & 0.20 \\
\hline 24 & S8 & Sekunder & 0.30 & & 0.30 \\
\hline 25 & S9 & Sekunder & 0.16 & & 0.16 \\
\hline 26 & $\mathrm{~S} 10$ & Sekunder & 5.21 & & 5.21 \\
\hline 27 & S11 & Sekunder & 0.69 & & 0.69 \\
\hline 28 & $\mathrm{P} 1$ & Primer & 1.53 & & 1.53 \\
\hline $\begin{array}{c}\text { Hf regional } \\
\mathrm{B}\end{array}$ & & & 14.64 & & 14.6 \\
\hline
\end{tabular}

Tabel 11. Rekapitulasi Hasil Perhitungan Hf alternatif 1

Tabel 12. Rekapitulasi Hasil Perhitungan Hf alternatif 2 
Sumber : hasil perhitungan

Rekapitulasi perhitungan head pompa dapat dilihat di tabel 13 dan tabel 14 .

Keterangan :

Hf = kehilangan energi pada pipa (m)

$\mathrm{Zb}=$ beda elevasi antara pompa dengan HU (m)

$\mathrm{V}=$ kecepatan rata rata pada pipa $(\mathrm{m} / \mathrm{s})$

$\mathrm{H}=$ head pompa $(\mathrm{m})$

\section{Operasi Pompa}

Plan A

Pompa dengan plan A dijalankan 1 pompa, untuk melayani HU 1, HU 2A, HU 2B dan HU 3. Sementara untuk HU 4A, HU 4B, HU 9A, HU 9B dan regional $\mathrm{B}$ menggunakan gravitasi.

Pola operasi untuk regional A, bergantian dengan SISTEM buka tutup katup yang ditempatkan pada pipa S10 dan pipa P2. Katup pada pipa P2 dibuka dan katup pada S10 dibuka pada pagi hari saat pompa diaktifkan untuk melayani HU 1, HU 2A, HU 2B dan HU 3 mulai pukul 05.00 dan 15.00. Sementara, katup pada S10 dibuka dan katup pada P2 ditutup saat pompa tidak beroperasi untuk melayani HU 4A, HU 4B, HU 9A, dan HU 9B. Asumsi bahwa pipa selalu terisi air, sehingga waktu untuk mengisi sepanjang pipa diabaikan.

Operasi untuk regional B menggunakan gravitasi, langsung diambil dari reservoir. Waktu pengaliran adalah 12 jam terhitung mulai pukul 06.00-18.00. Waktu operasi pompa untuk melayani HU 1, HU 2A, HU 2B dan HU 3 adalah 2 jam.
Tabel 13. Rekapitulasi Hasil Perhitungan Head Alternatif 1

\begin{tabular}{|c|c|c|c|c|c|c|c|}
\hline Dari & $\mathrm{Ke}$ & $\begin{array}{l}\text { Hf } \\
m\end{array}$ & $\begin{array}{c}\mathrm{V} \\
m / s\end{array}$ & $\begin{array}{l}\mathrm{Zb} \\
m\end{array}$ & $\begin{array}{l}\mathrm{H} \\
m\end{array}$ & $\begin{array}{c}\text { Over } \\
\text { head } 15 \% \\
m\end{array}$ & \\
\hline \multirow{15}{*}{ 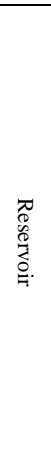 } & HU 1 & 1.40 & 0.30 & 9.50 & 10.90 & 12.54 & \\
\hline & HU $2 \mathrm{~A}$ & 1.81 & 0.30 & -1.50 & 0.32 & 0.37 & \\
\hline & HU 2B & 1.81 & 0.30 & 9.50 & 11.31 & 13.01 & \\
\hline & HU 3 & 1.51 & 0.30 & -5.50 & -3.99 & -4.59 & \\
\hline & HU 4A & 1.55 & 0.30 & -14.50 & -12.95 & -14.89 & Regional \\
\hline & HU 4B & 1.95 & 0.30 & -20.50 & -18.54 & -21.33 & A \\
\hline & HU 5A & 1.27 & 0.30 & -15.50 & -14.23 & -16.36 & \\
\hline & HU 5B & 1.72 & 0.30 & -22.50 & -20.77 & -23.89 & \\
\hline & HU 6A & 2.34 & 0.30 & -25.50 & -23.15 & -26.62 & \\
\hline & HU 6B & 3.00 & 0.30 & -26.50 & -23.50 & -27.02 & \\
\hline & HU 7A & 1.75 & 0.30 & -19.50 & -17.74 & -20.40 & \\
\hline & HU 7B & 2.21 & 0.30 & -21.50 & -19.28 & -22.18 & Regional \\
\hline & HU 8 & 5.17 & 0.30 & -28.50 & -23.32 & -26.82 & B \\
\hline & HU 9A & 3.77 & 0.30 & -17.50 & -13.72 & -15.78 & Regional \\
\hline & HU 9B & 4.08 & 0.30 & -17.00 & -12.91 & -14.85 & $\mathrm{~A}$ \\
\hline
\end{tabular}

\section{Plan B}

Pompa dengan plan B dijalankan 1 pompa, untuk melayani HU 1, HU 2A, HU 2B dan HU 3. Untuk melayani HU 4A, HU 4B, HU 9A, HU 9B dan regional $\mathrm{B}$ dengan gravitasi.

Pola operasi regional A, bergantian dengan buka tutup katup yang ditempatkan pada pipa S10 dan pipa $\mathrm{P} 2$. Untuk pagi hari katup pada pipa P2 ditutup dan katup pada S10 dibuka untuk melayani HU 1, HU 2A, HU 2B dan HU 3 mulai pukul 05.00 dan 11.00. saat sore hari, katup pada pipa S10 dibuka dan katup pada $\mathrm{P} 2$ ditutup untuk melayani HU 4A, HU 4B, HU 9A, HU 9B.

Pola operasi untuk regional B menggunakan gravitasi, langsung diambil dari reservoir. Waktu pengaliran adalah 12 jam terhitung mulai pukul 06.0018.00. Waktu operasi pompa untuk regional A 2 jam. 
Tabel 14. Rekapitulasi Hasil Perhitungan Head Alternatif 2

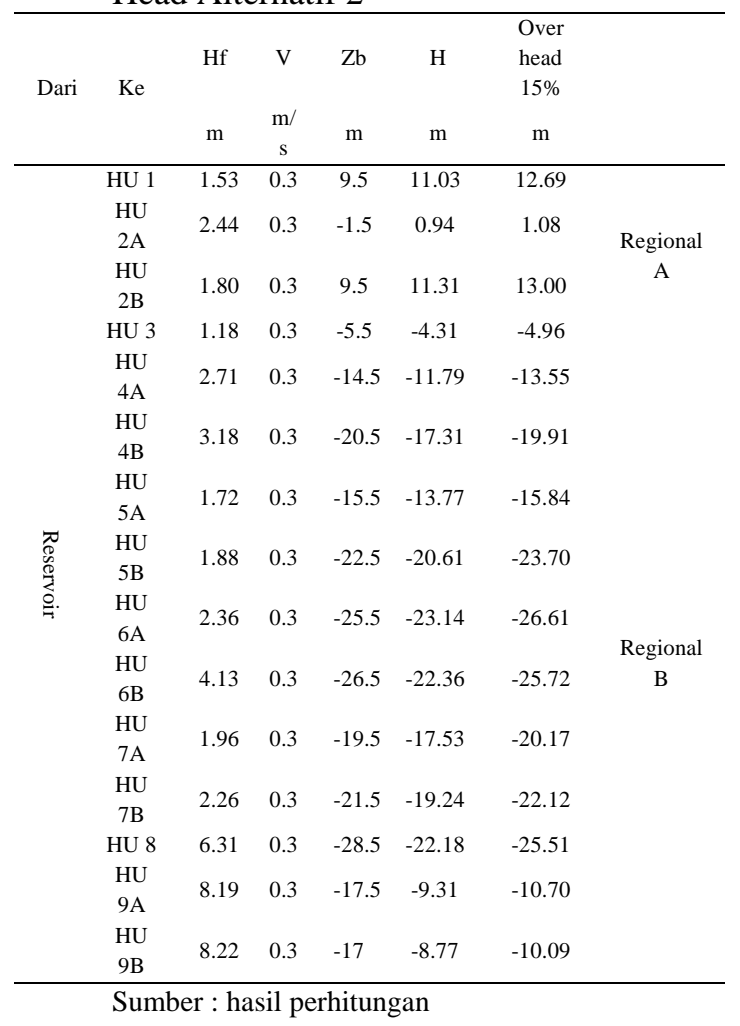

\section{Kapasitas Pompa}

Kapasitas pompa untuk alternatif 1 dan alternatif 2 adalah sama. Debit yang digunakan dalam jam pengoperasian pompa adalah debit efektif. Debit pada perencanaan jaringan alternatif 1 untuk melayani HU 1, HU 2A, HU 2B dan HU 3.

$Q e=\frac{\text { debitair }}{\text { waktuoperasi }}$

Debit untuk melayani HU 1, HU 2A, HU 2B dan HU 3 adalah $0.0011 \mathrm{~m}^{3} / \mathrm{dt}$ $=4.06 \mathrm{~m}^{3} / \mathrm{jam}$.
Direncanakan waktu pelayanan adalah 12 jam, sehingga kebutuhan HU 1, HU 2A, HU 2B dan HU 3 selama 12 jam adalah $48.79 \mathrm{~m}^{3}$.

Untuk memenuhi kebutuhan air sebesar $48.79 \mathrm{~m}^{3}$ dan pompa di operasikan selama 2 jam, kapasitas pompa yang digunakan adalah

$Q e=\frac{48.79}{2 \text { jam }}=24 \mathrm{~m}^{3} / \mathrm{jam}=0.4 \mathrm{~m}^{3} / \mathrm{mnt}$

\section{Debit Efektif Pompa}

Debit efektif pompa alternatir 1 dan alternatif 2 adalah sama.

Bahwa debit pompa dapat diketahui dengan cara membagi debit yang dibutuhkan (debit efektif) dengan jumlah pompa yang akan dipakai (Sualrso, 2004)

$Q e p=\frac{Q e}{\text { npompa }}$

Debit efektif untuk regional A

$Q e p=\frac{0.4}{1 \text { buah }}=0.4 \mathrm{~m}^{3} / \mathrm{mnt}$.

\section{Daya Pompa}

Perhitungan daya pompa (D) menggunakan diagram pemilihan pompa umum Sularso dan Tahara seperti Gambar 6 dan gambar 7 dengan total kehilangan energi pada pompa $(\mathrm{h})$ alternatif 1 adalah $13.01 \mathrm{~m}$ dan alternatif 2 adalah $13.00 \mathrm{~m}$. 


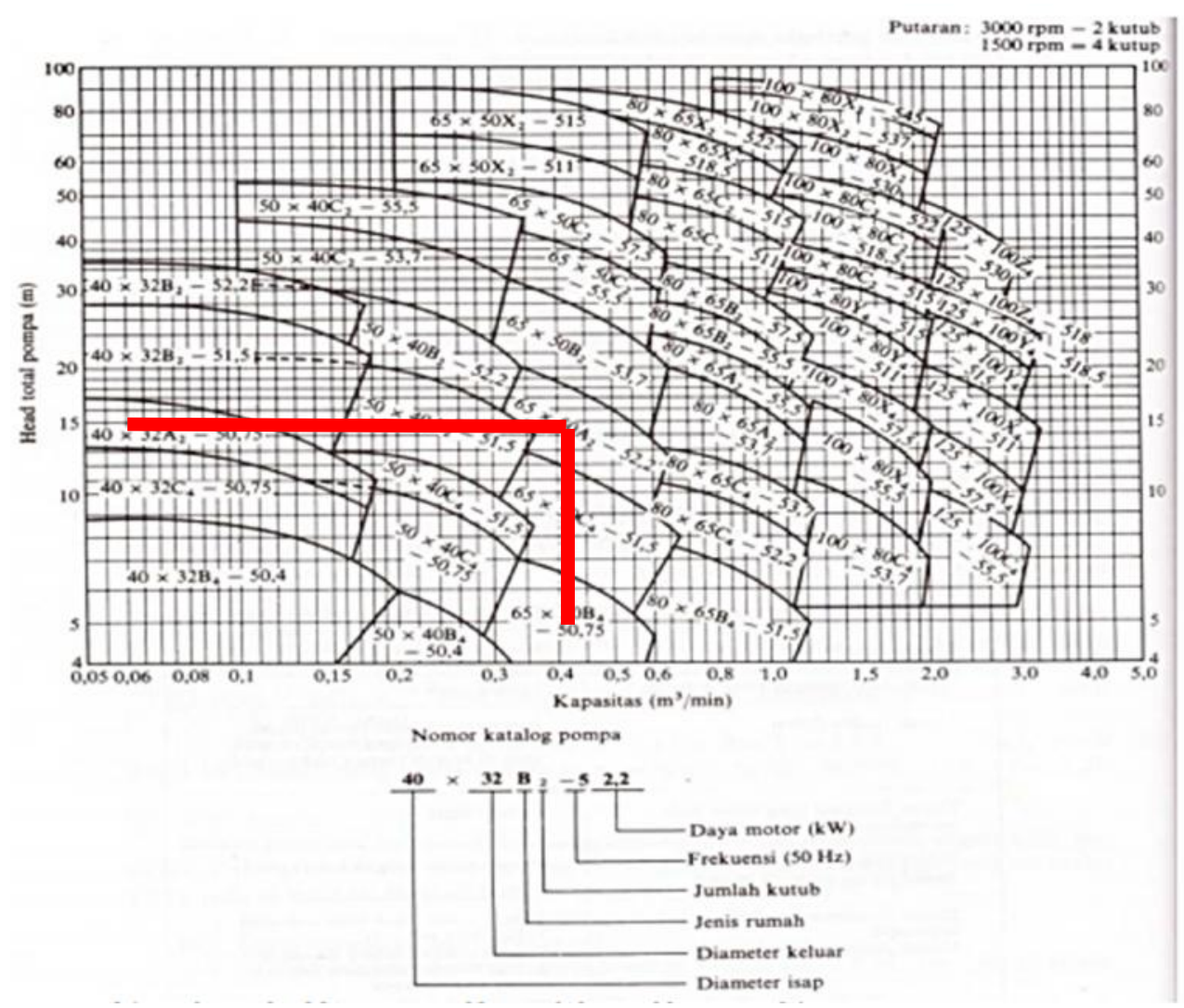

Gambar 6. Diagram pemilihan pompa alternatif 1

Dari hasil perhitungan didapatkan spesifikasinya pompa sama untuk alternatif 1 dan alternatif 2 .

Dari gambar 6, diagram pemilihan pompa, diperoleh spesifikasi pompa yang digunakan adalah $65 \times 50 \mathrm{~A}_{2}-5$ 2.2 dan kapasitas pompa $0.4 \mathrm{~m}^{3} /$ menit $=6.6$ liter/detik dengan spesifikasinya sebagai berikut:
Diameter isap $\quad=0,065 \mathrm{~m}$
Diameter keluar $=0,050 \mathrm{~m}$
Jumlah katup $=2$ Katup
Daya Motor $\quad=2.2 \mathrm{~kW}$
$=2200 \mathrm{Watt}$

Rekapitulasi operasi pompa dapat dilihat pada tabel 15 . 


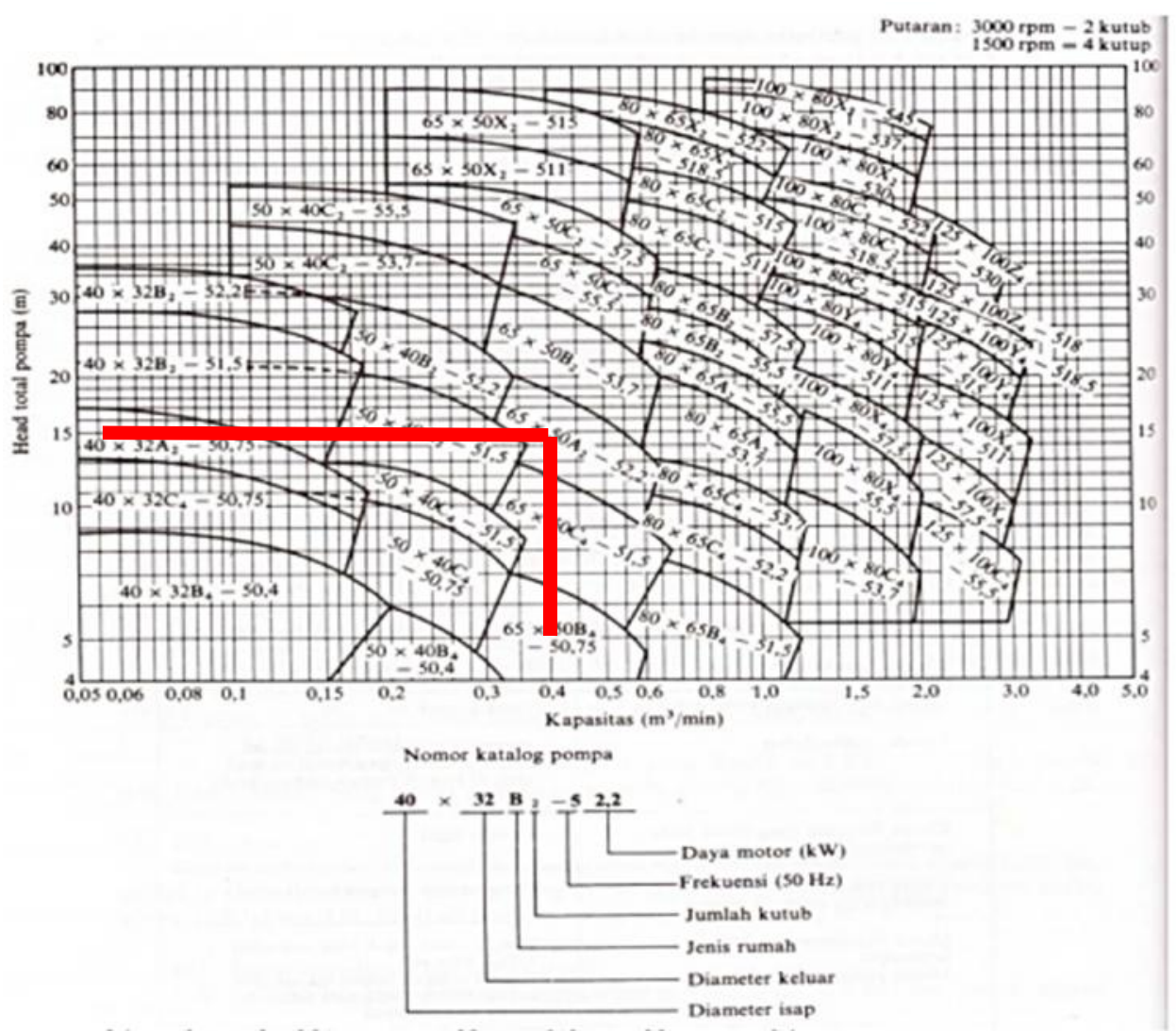

Gambar 7. Diagram pemilihan pompa alternatif 2

Tabel 15. Rekapitulasi Perhitungan Operasi Pompa

\begin{tabular}{|c|c|c|c|c|c|c|}
\hline PIPA & PLAN & REG & Head & Q & POLA OPERASI & $\begin{array}{l}\text { WAKTU } \\
\text { OPERASI }\end{array}$ \\
\hline & & & $\mathrm{m}$ & $\mathrm{m}^{3} / \mathrm{mnt}$ & & \\
\hline \multirow[t]{2}{*}{ Alternatif 1} & A & A & 13.01 & 0.4 & $\begin{array}{l}\text { Pompa dinyalakan pada pagi dan } \\
\text { sore, dengan sistem buka tutup } \\
\text { katup untuk melayani HU 1, HU } \\
\text { 2A, HU 2B dan HU 3 }\end{array}$ & 2 \\
\hline & B & A & 13.01 & 0.4 & $\begin{array}{l}\text { Pompa dinyalakan pada pagi hari, } \\
\text { pada pukul } 05.00 \text { dan pukul } 11.00\end{array}$ & 2 \\
\hline \multirow[t]{2}{*}{ Alternatif 2} & A & A & 13.00 & 0.4 & $\begin{array}{c}\text { Pompa dinyalakan pada pagi dan } \\
\text { sore, dengan sistem buka tutup } \\
\text { katup untuk melayani HU 1, HU } \\
\text { 2A, HU 2B dan HU 3 }\end{array}$ & 2 \\
\hline & B & A & 13.00 & 0.4 & $\begin{array}{l}\text { Pompa dinyalakan pada pagi hari, } \\
\text { pada pukul } 05.00 \text { dan pukul } 14.00\end{array}$ & 2 \\
\hline
\end{tabular}

Sumber : hasil perhitungan

Dari table 15, rekapitulasi pola operasi, dipilih pipa dengan alternatif 1 Plan A. Karena, kehilangan energi total lebih kecil daripada alternatif 2 .

\section{Simpulan}

Dalam penelitian ini dapat disimpulkan adalah:

- Jumlah penduduk proyeksi tahun 2041 sebesar 6084 orang dengan 
Jurnal Aplikasi Teknik Sipil ISSN.1907-753

kebutuhan per orang 20 1/hari dan

Bersih Permen PU No:

kebutuhan total 1 desa adalah 152.1

18/PRT/M/2007. Jakarta.

$\mathrm{m}^{3} /$ hari

- Metode yang digunakan adalah metode geometrik, karena nilai korelasi nya mendekati 1 yaitu sebesar 0.999 .

- Pelayanan distribusi air menggunakan alternatif 1 dan pola operasi menggunakan Plan A dengan kebutuhan air Untuk regional A sebesar $103.5 \mathrm{~m}^{3} /$ hari dan $48.5 \mathrm{~m}^{3} /$ hari untuk regional $\mathrm{B}$.

- Pola operasi yang digunakan adalah dengan masing masing regional dilayani 1 pompa dan dijalankan bersama sama dengan sistem buka tutup katup. Untuk regional A dengan debit sebesar $0.4 \mathrm{~m}^{3} / \mathrm{mnt}$ pompa dinyalakan selama 2 jam pagi dan sore.

\section{Daftar Pustaka}

Badan Pusat Statistik. 2016. Desa Kalisat Dalam Angka. Pasuruan: BPS

Mangkudiharjo, Sarwoko. 1985. Penyediaan Air Bersih. Surabaya

Menteri Kesehatan Republik Indonesia. 1990. Syarat-syarat dan Pengawasan Kualitas Air Peraturan Menteri Kesehatan Republik Indonesia No:416/MENKES/PER/IX/1990.

Jakarta.

Menteri Pekerjaan Umum. 2007. Penyelenggaraan Pengembangan Sistem Penyediaan Air 